\title{
Effect of Surface Oxides on the Melting and Solidification of 316L Stainless Steel Powder for Additive Manufacturing
}

\begin{abstract}
XINLIANG YANG, FENG GAO, FENGZAI TANG, XINJIANG HAO, and ZUSHU LI
Surface oxidation of metallic powders may significantly affect their melting and solidification behavior and limit their service life in the additive manufacturing (AM) process. In the present work, three levels of surface oxide concentration were prepared on AM-grade 316L stainless steel powders, and their melting and solidification behavior was systematically studied through in-situ observation, advanced characterization, phase-field modeling, and theoretical analysis. $\mathrm{Si}, \mathrm{Mn}$, and $\mathrm{Cr}$ participated in the oxidation reaction in powder with low and medium oxygen contents, whereas $\mathrm{Fe}$ was involved in the oxidation reaction for the powder samples with high oxygen content. A higher full melting temperature is observed to lead to an integrated melt pool in the melting of the highly oxidized powder, which is due to the reduced permeability produced by the oxide cage effect. For the droplet samples prepared from high oxygen powders, the inclusion with increased volume fraction and coarsened size is attributed to the agglomeration of inclusion particles with the residual oxide in the melt. In the high oxygen powder fusion scenario, an undesired coarse columnar grain structure with a high aspect ratio is formed in the current nonequilibrium solidification process, and a consistent microstructure is predicted using solidification conditions with a high cooling rate and high thermal gradient similar to the conventional AM process. In contrast, fine equiaxed grains in the experiment and slim columnar grains with a small aspect ratio in the phase-field simulation are obtained for the low oxygen powder condition. This study illustrates the effect of powder oxide from a processing aspect and provides insight into the importance of improving the service life of powder feedstock by effectively reducing the surface oxidation process on the powder surface.
\end{abstract}

https://doi.org/10.1007/s11661-021-06405-3

(C) The Author(s) 2021

\section{INTRODUCTION}

MetAL powder, as one unique branch of metallic feedstock, has been widely used in structural applications through powder metallurgy (PM), spray deposition, and newly emerged additive manufacturing (AM) ${ }^{[1]}$ The excellent chemical uniformity of rapidly solidified metal powder by the gas/water atomization process emphasizes its advantage compared to the conventional bulk counterpart. However, surface oxidation is inevitable in powder production, handling, and processing for metals and alloys with high oxygen affinity due to exposure of their high specific surface area to the environmental atmosphere. ${ }^{[2]}$ As the

XINLIANG YANG, FENGZAI TANG, and ZUSHU LI are with the WMG, University of Warwick, Coventry CV4 7AL, UK. Contact e-mail: Z.Li.19@warwick.ac.uk FENG GAO is with the BCAST, Brunel University London, Uxbridge UB8 3PH, UK. XINJIANG $\mathrm{HAO}$ is with the Liberty Powder Metals, Materials Processing Institute, Eston Road, Middlesbrough, TS6 6US, UK.

Manuscript submitted May 16, 2021; accepted July 16, 2021.

Article published online July 31, 2021 dominant material in metallic powder production, steel powders typically present surface oxidation in the form of oxides due to their low oxygen solubility in the Fe matrix. The chemistry of the formed oxides is primarily dependent on the oxygen-gettering elements in metals and alloys. ${ }^{[3]}$

Extensive investigation has been carried out to characterize surface oxides of various steel powders prepared using different atomization methods, including study of their influence on the compacting, sintering, and postprocessing of PM components. ${ }^{[4-8]}$ The nanosized surface oxide layer ${ }^{[9]}$ decreases the neck growth kinetics of neighboring particles by reducing element diffusion, which leads to an increased sintering temperature and/or extended processing time. Both are detrimental for material oxidation control in the PM process. ${ }^{[10]}$ As a result, the excessive oxide from powder materials greatly affects the mechanical performance of PM-fabricated steel components.

The powder fusion-based AM process has broadened the application of metallic powder from solid-state sintering to solidification (liquid-state process). ${ }^{[1]}$ With the fast-growing AM market, research has covered the 
compatibility of powders with the AM process to achieve a better performance for as-built components, ${ }^{[12,13]}$ e.g., the powder flowability, ${ }^{[14]}$ sphericity, ${ }^{[15]}$ and packing density. ${ }^{[16]}$ Powder feedstock suitable for rapid solidification is highly desired in the AM industry ${ }^{[17]}$ because it is a prerequisite for AMs to march into the mainstream business of structural components. Although these existing efforts have helped to understand the evolution of the materials in the powder fusion-based AM process, the influence of powder characteristics remains underexplored. It is critical to understand the relationship between powder quality and the performance of the built component, such as, for instance, the surface oxide on the powder material. Unlike the PM process, the application of AM to steel powder is still challenging. ${ }^{[18]}$ The feedstock powder in the powder bed is unable to completely transform into the present geometry of the targeting component due to the nature of the process design. ${ }^{[19]}$ By reusing the powders in the powder bed, a large portion of the material may experience multiple cycles of the processing environment. Both the matrix element $\mathrm{Fe}$ and the alloying elements $\mathrm{Cr}$, $\mathrm{Mn}$, and $\mathrm{Si}$ have high oxygen affinity, which results in a significant amount of oxidation during conventional AM-processing conditions. ${ }^{[2]}$

In the previous studies of $\mathrm{Fe}-\mathrm{Cr}-\mathrm{Ni}$ stainless steel powders, ${ }^{[20,21]}$ spatter powders from the laser-powder bed fusion (L-PBF) process were collected for chemical and morphological characterization. As strong oxide formers, $\mathrm{Si}, \mathrm{Mn}$, and $\mathrm{Cr}$ oxides are observed in the collected powders. Although a study of nano-oxides inside $18 \mathrm{Ni}$-300 maraging steel ${ }^{[22]}$ suggested a positive strengthening prospect for nano-oxide inclusions in the laser fusion process, the source of such oxides was not identified, which might arise from surface oxidation during PBF or from prealloyed powder atomization. In contrast, the effect of oxides on the mechanical properties of AM components has been reported extensively. Quinn et al. ${ }^{[23]}$ discussed the influence of recycled $316 \mathrm{~L}$ stainless steel powder with oxide contamination on the performance of an as-built component and the layering process during L-PBF. In a study of $12 \mathrm{CrNi} 2$ steel with various oxygen contents, ${ }^{[24]}$ a severely decreased tensile property was reported to be attributed to a large portion of the surface oxide layer on the starting powder with a high oxygen content. Gatto et al. ${ }^{[25]}$ reported the degradation effects for powder contamination on the fatigue property of an as-built $18 \mathrm{Ni}-300$ maraging steel component, even though the average chemical composition of the powder fell in the technical specification. Further to the postmortem analysis, Leung et al. ${ }^{[26]}$ reported the laser-powder interaction of $\mathrm{Fe}-36 \mathrm{Ni}$ Invar36 alloy in an L-PBF simulator using synchrotron $\mathrm{X}$-ray imaging and diffraction methods. The porosity generated in the as-solidified melt track is attributed to the high oxygen contents in the powder feedstock. According to the above discussion, it is clear that the performance of a component built by the powder fusion-based AM process is highly dependent on the oxide content in the powder feedstock. However, information for the effect of surface oxides on the melting and solidification of steel powder is still lacking.
A clear understanding of such phenomena would provide insight into the melting and solidification of powder materials. In the current study, we aim to understand the influence of surface oxides on the melting and solidification behavior of steel powder and the corresponding as-solidified microstructure by combining experimental observations with advanced characterization techniques, thermodynamic calculations, columnar to equiaxed transition (CET) analysis, and phase-field simulations. To achieve this target, a high-temperature confocal laser scanning microscope (HT-CLSM) was utilized for in-situ observation of the powder melting and solidification process.

\section{MATERIALS AND METHODS}

\section{A. Experimental Design of $316 L$ Powder with Varying Oxygen Content}

The as-received $316 \mathrm{~L}$ powder produced by inert gas atomization is presented in Figure 1. The particle size distribution and particle sizes by number fraction are listed in Figure 1(b). The chemical composition (wt pct) of the as-received powder is $\mathrm{Cr} 15.77$, Ni 10.22, Mo 2.12, Mn 1.26, Si 0.63, C 0.0147, S 0.0142, P 0.038, O 0.0355, and $\mathrm{Fe}$ is the balance. The chemical composition of metallic elements was determined by the inductively coupled plasma mass spectrometry (ICP-MS) method. Carbon, sulfur and phosphorus contents were obtained by combustion analysis. The oxygen content was measured by inert gas fusion. ${ }^{[27]}$

To understand the effect of surface oxides on the powder melting and solidification behavior, three types of powder were individually selected to present different concentrations of powder surface oxides. The as-received fresh powder was used as a low oxygen powder. The same batch of $316 \mathrm{~L}$ powder was subjected to multiple cycles of the L-PBF process until the chemical composition no longer fulfilled the manufacturing specification (oxygen content). These rejected powders were collected as $316 \mathrm{~L}$ powder with medium oxygen content. To study the extreme conditions reported in the literature, ${ }^{[24,26]}$ the as-received fresh $316 \mathrm{~L}$ powder was artificially oxidized in an atmosphere-controlled furnace at $800^{\circ} \mathrm{C}$ for 20 minutes with an airflow of $0.1 \mathrm{~L} / \mathrm{min}$. This oxidized powder was used as high oxygen powder.

For simplicity, the as-received fresh $316 \mathrm{~L}$ stainless steel powder is hereafter referred to as the powder containing low surface oxide (low $\mathrm{O}$ powder) and the powder collected from the L-PBF process, and artificially oxidized powder is referred to as the powder containing medium and high surface oxide contents (medium $\mathrm{O}$ powder and high $\mathrm{O}$ powder), respectively, as listed in Table I.

\section{B. In-Situ Observation of the Melting and Solidification Phenomena of 316L Powders}

Due to the high heating and cooling rate of the laser-powder interaction, capturing the solidification feature in the AM process presents a great challenge. A 


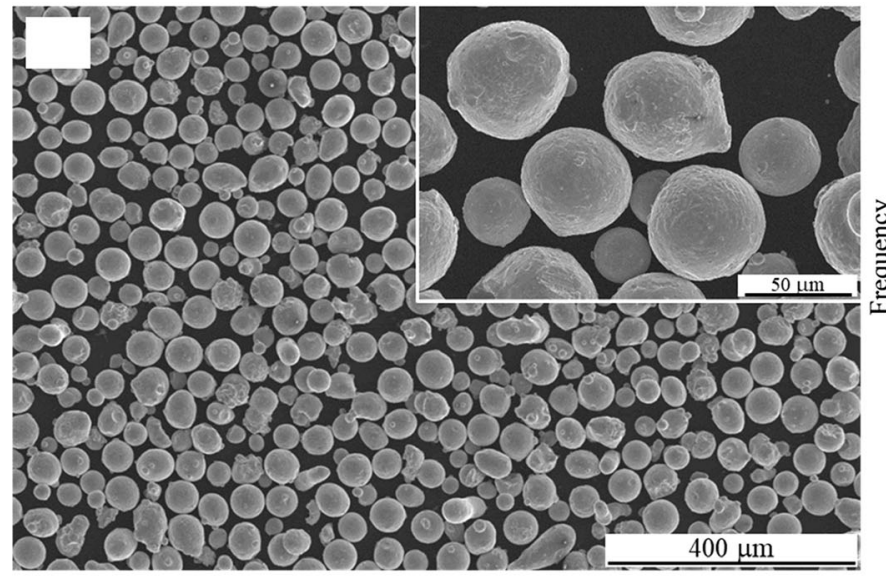

(a)

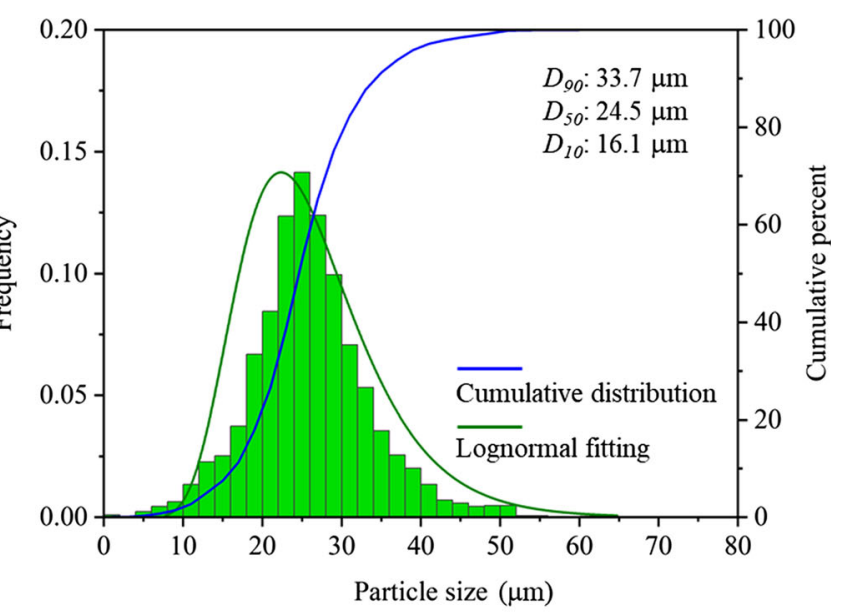

(b)

Fig. 1-Morphology of the as-received 316L stainless steel powders (a) and their particle size distribution (b).

high temporal resolution synchrotron X-ray facility ${ }^{[26]}$ provides the opportunity to observe porosity formation in situ in the PB-SLM process. A characterization approach with higher morphological contrast is desired to capture the information for liquid/solid phase transformation in the presence of oxides. Localized powder fusion by laser/electron beams is a complicated physical phenomenon involving heat-induced solid-liquid phase transformation, laser/electron beam-induced local ionization, ${ }^{[30]}$ and powder-packing conditions. To study the effect of surface oxides on the melting and solidification of powder material, the design of the experiment has to filter out the other variables and keep the heat input. Here, a Yonekura VL2000DX-SVF17SP high-temperature confocal laser scanning microscope (HT-CLSM) was utilized to observe the melting and solidification behavior of $316 \mathrm{~L}$ powders with varying oxide concentrations in situ. A schematic illustration of the HT-CLSM is presented in Figure 2(a). The microscope contains two subsystems: an environment furnace and an optical acquisition unit. The environment furnace is able to provide a maximum temperature up to $1700^{\circ} \mathrm{C}$ with heating and cooling rates of up to 20 and $100 \mathrm{~K} / \mathrm{s}$ (helium-forced cooling), respectively, ${ }^{[31]}$ obtained by infrared radiation heating, which helps to avoid high-energy beam-local ionization. The furnace is compatible with inert gas $\left(\mathrm{Ar}, \mathrm{N}_{2}\right)$, reductive gas $\left(\mathrm{H}_{2}, \mathrm{CH}_{4}\right)$, oxidizing gas $\left(\mathrm{CO}_{2}\right.$, air, $\left.\mathrm{O}_{2}, \mathrm{H}_{2} \mathrm{O}\right)$, and vacuum ${ }^{[32]}$ to simulate the high-temperature behavior of the gas-liquid-solid reaction under a range of environmental conditions. The optical acquisition unit is composed of a laser generator for the violet laser source with a wavelength of $405 \mathrm{~nm}$, an optical focusing control system, and a CCD camera that is used to image the sample behavior in the environment furnace through the quartz window.

The processing parameter in Figure 2(b) is programmed for in-situ observation in the HT-CLSM to reveal the localized powder melting and solidification behavior in the nonequilibrium state with a high temperature gradient with consideration of the maneuver tolerance. For each powder condition, seven sets of experiments were conducted with a powder dose of $\sim 0.25 \mathrm{~g}$, which was solidified as a semispherical droplet (solidified droplet) with a diameter of less than $2 \mathrm{~mm}$; this droplet was designed by considering reported work studying the laser/metallic material interaction in single-spot fusion. ${ }^{[26,33]}$ Benefitting from this consideration, poor powder spreadability-induced packing defects can be excluded.

\section{Theoretic Analysis}

The thermodynamic calculation was processed with the FactSage 7.3 software package (GTT-Technologies). The Phase Diagram module was utilized for oxide phase prediction as a function of oxygen partial pressure and temperature. The Equilib module was used for determining the theoretical liquidus and solidus of $316 \mathrm{~L}$ stainless steel with varying oxygen content, the equilibrium phase calculation in the oxidation reaction, and the equilibrium phase evolution in the melting process with increasing temperature. The input data included the powder chemical composition and the relevant oxygen partial pressure under the given conditions. The database of FactPS, FToxid, and FSstel were used, and monoxide, spinel, corundum, bixbyite, braunite, and rhodonite were selected as oxide solution candidates. The commercial software MICRESS ${ }^{\circledR}$ (ACCESS e.V.) was used for the phase-field simulations of the grain morphology evolution. The details for the theory and the setup have been previously described in Reference 34 .

\section{Characterization of Powders and Solidified Droplets}

Scanning electron microscopy (SEM, Jeol 7800) and dual-beam focused ion beam (FIB) SEM (Versa FEI, now part of Thermo Fisher Scientific) were employed to study the morphology of $316 \mathrm{~L}$ powders and solidified droplets with different oxide concentrations, during which both secondary electron (SE) and backscattered electron (BSE) images were acquired. The chemical compositions of the samples were examined in detail 
using energy-dispersive X-ray spectroscopy (EDS, Oxford Instruments) at 10 to $15 \mathrm{kV}$ and wavelength-dispersive X-ray spectroscopy (WDS, Oxford Instruments) at $30 \mathrm{kV}$.

To study the surface oxides on the $316 \mathrm{~L}$ powders, cross-sectional TEM (transmission electron microscopy) samples were prepared from the oxide layer attached to the steel matrix using the standard in-situ lift-out technique. ${ }^{[35]}$ Scanning TEM (STEM) analysis was conducted using a Talos F200X microscope (FEI, now part of Thermo Fisher Scientific) operating at $200 \mathrm{kV}$. This microscope was equipped with a Super-X EDS system with four integrated silicon drift detectors, supporting a solid angle of 0.9 srad that offered fast chemical composition mapping. During STEM analysis, both high-angle annular dark-field (HAADF) and bright-field (BF) images were acquired simultaneously using Velox ${ }^{\mathrm{TM}}$ software.

The as-solidified droplet samples were prepared through a standard metallographic procedure with final vibration polishing. Microstructural and crystallographic analyses were conducted using a Symmetry® EBSD detector (Oxford Instrument) fitted within a Jeol 7800 SEM at $20 \mathrm{kV}$ with an indexing speed of $\sim 2000$ fps. A step size of $1.5 \mu \mathrm{m}$ was used for EBSD data acquisition. The statistical analysis of the inclusion (oxide) in the as-solidified droplet was carried out by imaging analysis using Image J $1.49 \mathrm{v}$ software with 500 SEM micrographs under each powder condition.

An image processing method was used to determine the solidification completion temperature. Each captured microstructure image has a unique gray value profile. During such a first-order phase transformation, the microstructure evolution will significantly change the profile of the gray value for the captured microstructure image. Once the solidification is completed, the microstructure will remain constant. By using ImageJ $1.49 \mathrm{v}(\mathrm{NIH})$ software, each frame of the recorded microstructure image can be transformed into a unique gray value curve. By a mathematical comparison of the individual profiles, a critical temperature point can be identified as the point after which the change in neighboring gray value profiles is kept at a minimum compared to the overall gray value difference between the liquid state and fully solidified microstructure.

\section{RESULTS}

\section{A. Surface Oxide Analysis for Different 316L Powders}

As the framework of surface oxide selection on steel powder materials has been well established for PM purposes, the outcomes were obtained through surface-sensitive approaches, such as XPS, AEM, and SIMS. According to Hedberg et al., ${ }^{[8]}$ an oxide layer with a thickness of $\sim 3 \mathrm{~nm}$ enriched with $\mathrm{Si}, \mathrm{Mn}, \mathrm{Fe}$, and $\mathrm{Cr}$ is expected to be present on a fresh $316 \mathrm{~L}$ powder surface after argon gas atomization. In the current investigation, the focus is on excessive oxide/contamination with submicron to micron sizes on metal powder surfaces at different concentrations.
The surface morphology of the three types of powder is shown in Figure 3. A clean metal surface is observed for the low $\mathrm{O}$ powder with a few micron-sized oxides present on the surface (Figures 3(a) and (b)). The medium $\mathrm{O}$ powder in Figure 3(c) shows a wide range of oxides on the powder surface. From the inset of Figure 3(d), the resultant oxides are present in large patches with dark contrast accompanied by small compact particles. The high $\mathrm{O}$ powder in Figures 3(e) and (f) shows a globally oxidized surface.

By considering the oxygen affinity of alloying elements in $316 \mathrm{~L}$ stainless steel, ${ }^{[36]}$ the EDS mapping for oxygen elements, strong oxide-forming elements ( $\mathrm{Si}$, $\mathrm{Mn}$, and $\mathrm{Cr}$ ), and matrix Fe is presented in Figure 3. A detailed point analysis for the medium $\mathrm{O}$ powder and high $\mathrm{O}$ powder is listed in Table II. In the element maps for the low $\mathrm{O}$ powder shown in Figure 3(b), $\mathrm{Si}$ and $\mathrm{O}$ signals are observed in the same region of the powder surface with a weak signal from Mn. The element maps in Figure 3(d) show the chemical information for the medium $\mathrm{O}$ powder surface. The intense $\mathrm{Si} / \mathrm{Mn}$ signal overlaps in the large patch area, and the Si-free area in the large patch is occupied by $\mathrm{Cr}$. From the element maps for the high $\mathrm{O}$ powder element in Figure 3(f), a large portion of the powder surface is occupied by the Fe-intensified area, which overlaps with the oxygen-rich region. The chemical formula of this oxide is determined to be $\mathrm{Fe}_{2} \mathrm{O}_{3}$ according to the point analysis of $\mathrm{P} 3$ and $\mathrm{P} 4$ in Figure 3(f). In the meantime, weak contrasts for $\mathrm{Cr}$ and $\mathrm{Si}$ are also noticed.

\section{B. Melting and Solidification Behavior of Different $316 \mathrm{~L}$ Powders}

Snapshots for the in-situ observation of powder melting and solidification in HT-CLSM are presented in Figure 4. For the low $\mathrm{O}$ powder shown in Figures 4(a) through (e), the bubbling phenomenon is observed in the fully molten liquid (Figures 4(c) and (d)), and a clean surface for the austenite grain is exhibited when solidification is completed (Figure 4(e)). The bubbling could be due to the gas wrapped in the melt pool, which is then driven out by the buoyant force. In contrast, the oxides are released to the top of the melt pool and cover the droplet surface in the solidification of the melt from the medium $\mathrm{O}$ powder (Figures 4(h) and (i)) and the high $\mathrm{O}$ powder (Figures $4(\mathrm{~m})$ and $(\mathrm{n})$ ). During the solidification of the melt from medium $\mathrm{O}$ powder, thin and porous oxides gather on the surface of the melt pool, forming an integrated network (Figures 4(h) and (i)). With a higher oxide content in high $\mathrm{O}$ powder, thick and condensed patches of oxides are observed on the top of the melt in Figures 4(m) and (n). Once solidification occurs, a smooth and fine surface for the as-solidified droplet is observed in the low $\mathrm{O}$ powder experiment, as shown in Figure 4(p), which suggests that the absence of surface oxides leads to a clean as-solidified surface. On the other hand, the top surface of the medium $\mathrm{O}$ droplet is contaminated by large patches of oxides (Figure 4(q)). Meanwhile, the coarse austenite dendrites observed on the droplets suggest that columnar grain growth may occur during solidification. 


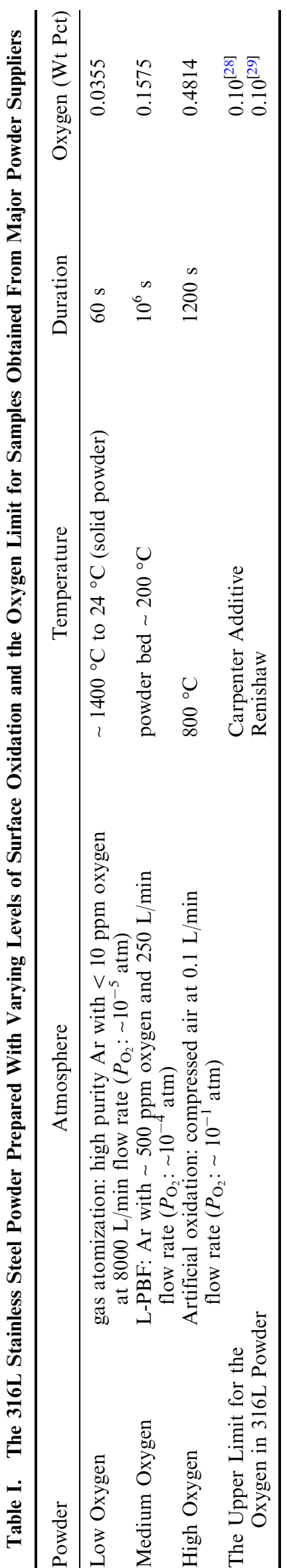

Figure 5 shows the full melting temperature of the powders and the temperature of the primary phase completely solidified in the observation field. The full melting temperature of the metallic powder is defined as the temperature when the individual powder melt is integrated into one liquid pool, which can be the same as or higher than the theoretical liquidus. An increase in the full melting temperature is noticed with increasing oxide content in the powder. In the meantime, the temperatures for solidification completion for the three types of powders are consistent with the theoretical solidus of the alloy.

\section{The As-Solidified Microstructure of the Droplets Prepared Using Various 316L Powders}

The inverse pole figure (IPF) image with the overlapping grain boundary (GB) map and the corresponding distribution of the grain boundary misorientation are presented in Figure 6. A clear microstructural difference between the droplets solidified by the low $\mathrm{O}$ powder and high $\mathrm{O}$ powder indicates a change in the austenite grain growth pattern. A clear equiaxed grain morphology is observed in the low $\mathrm{O}$ droplet (Figure 6(a)), while columnar growth results in straight grain boundaries, and large grain blocks are observed for the cases of the medium $\mathrm{O}$ powder (Figure 6(b)) and high $\mathrm{O}$ powder (Figure 6(c)). By combining with Figure 4(q), a typical columnar growth for austenite grains is observed. A fine and equiaxed microstructure with an average grain size of $90 \mu \mathrm{m}$ is observed in the low $\mathrm{O}$ droplets, while the medium and high $\mathrm{O}$ droplets show a coarse columnar structure with average primary dendrite arm spacings (DASs) of 145 and $244 \mu \mathrm{m}$, respectively. The total number of austenite grains/dendrites measured for the high $\mathrm{O}$ droplets and medium and low $\mathrm{O}$ droplets is 350 and 500 , respectively.

The grain boundary and related misorientation distribution in the as-solidified droplets are also important to understand the solidification behavior of the droplets obtained from different powders. In the current analysis, $15 \mathrm{deg}$ is used as the threshold misorientation to distinguish high-angle grain boundaries (HAGBs) from low-angle grain boundaries (LAGBs) in the IPF + GB map (Figures 6(a) to (c)). The HAGBs $(\geq 15 \mathrm{deg}$ ) in black define the boundaries of individual austenite grains. The LAGBs are highlighted in white with a misorientation angle lower than $15 \mathrm{deg}$ to separate the substructure within the individual grains. By examining the as-solidified high $\mathrm{O}$ droplets (Figure 6(c)), a high LAGB fraction of 65 pct in the total length of grain boundaries is obtained. The low $\mathrm{O}$ and medium $\mathrm{O}$ droplets show 53 and 49 pct LAGB fractions, respectively. Normally, the as-solidified sample is expected to present a HAGB-dominant feature as the solidification approaches the low residual stress condition. The high LAGB fraction of the high $\mathrm{O}$ droplet may be related to the surface oxide on the high $\mathrm{O}$ powder. The dimensions of the substructure outlined by the LAGB fall onto a similar scale as the initial powder size. This indicates that a portion of the oxides from the high $\mathrm{O}$ powder are trapped in the melt pool during solidification, which 


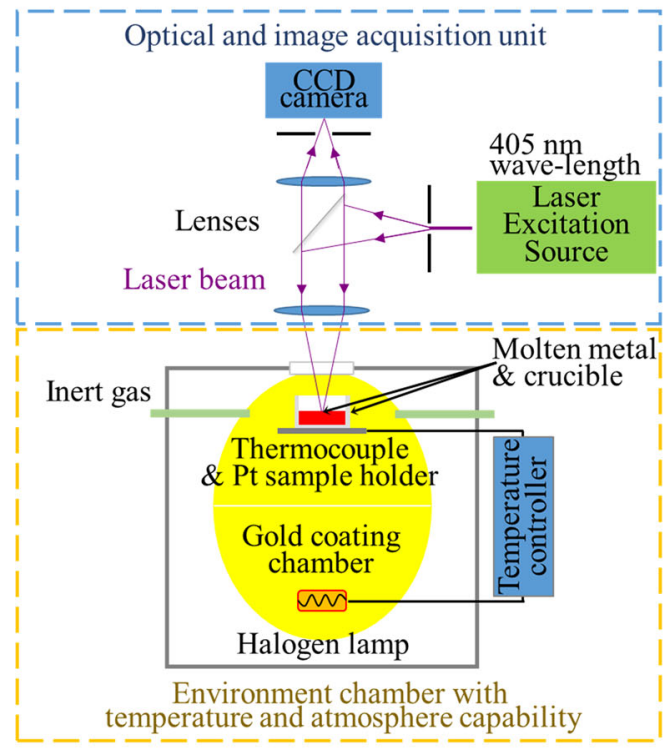

(a)

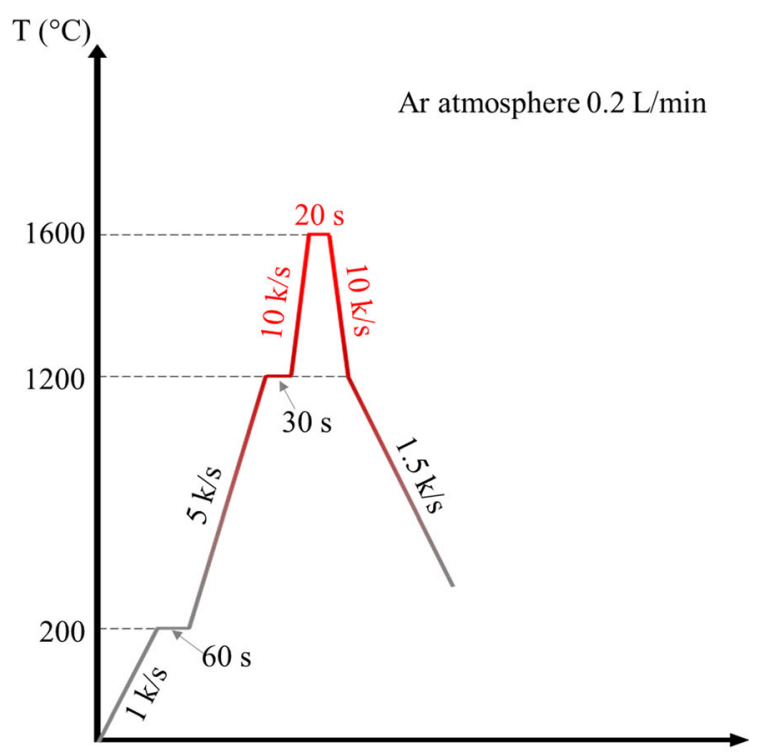

(b)

Fig. 2-Schematic illustration of the high-temperature confocal laser scanning microscope (HT-CLSM) (a) and the processing parameters used in the powder melting and solidification experiment $(b)$.

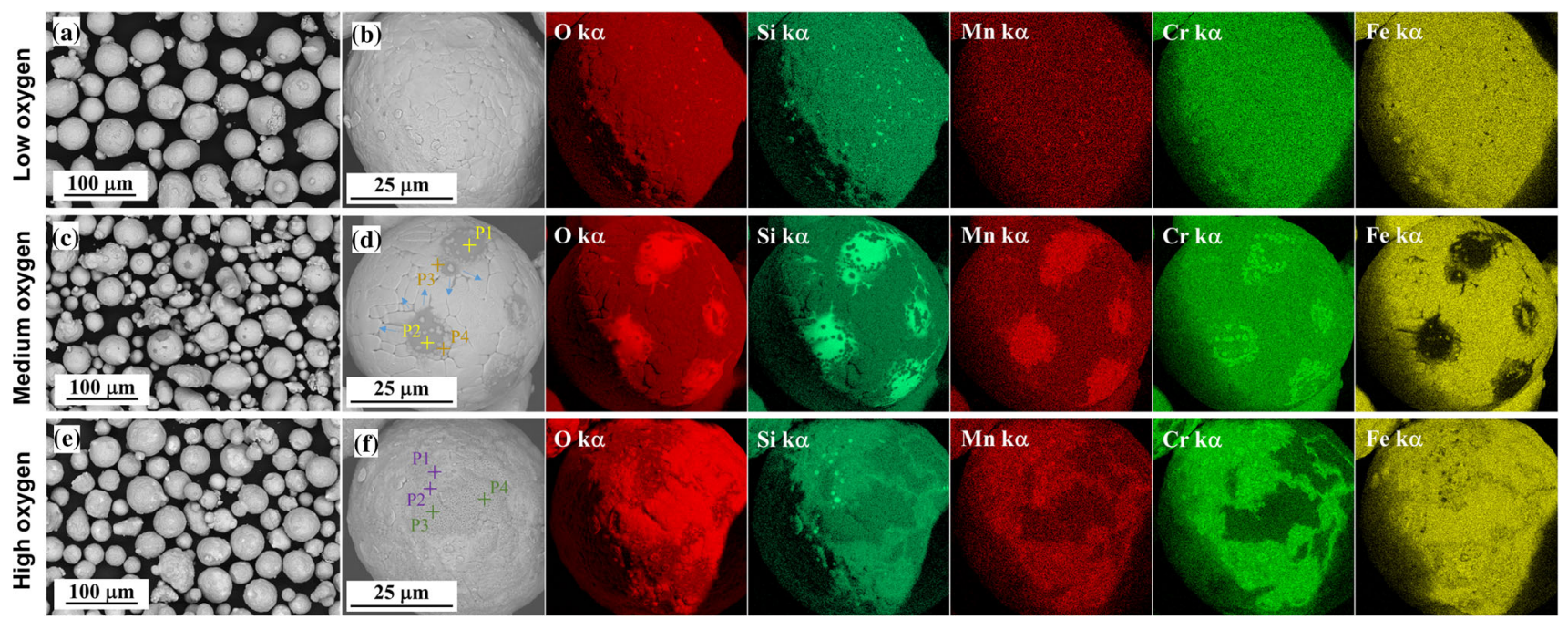

Fig. 3- Surface morphology and EDS element mapping for the powder surface to indicate the excessive oxide compounds formed on the powder surface under different oxidation conditions: $(a)$ and $(b)$ the low O powder, $(c)$ and $(d)$ the medium $\mathrm{O}$ powder, and $(e)$ and $(f)$ the high $\mathrm{O}$ powder.

hinders the solidification front and results in a local crystallographic misorientation on both sides of the obstacle oxides.

\section{DISCUSSION}

\section{A. Surface Oxidation of the $316 \mathrm{~L}$ Powders Under Different Conditions}

In general, the thermodynamics and kinetics of oxide formation are determined by the temperature, exposure period, oxygen partial pressure, and powder chemical composition. ${ }^{[37]}$ The calculated oxygen solubility in the austenite phase is extremely low $\left(\sim 10^{-15}\right.$ wt pct at 800 ${ }^{\circ} \mathrm{C}$ ), which suggests that the oxygen in the powder materials has to be present in the form of oxide compounds.

The extremely short exposure time and low oxygen partial pressure in the low $\mathrm{O}$ powder condition $\left(P_{\mathrm{O}_{2}}=\sim 10^{-5} \mathrm{~atm}\right)$ limited the oxidation reaction only to the high oxygen affinity elements $(\mathrm{Si}, \mathrm{Mn})$. The oxide phase diagram in Figure 7(a) suggests that the corundum-type oxide can form in the conditions experienced by the medium $\mathrm{O}$ powder and high $\mathrm{O}$ powder d (Table I) along with minor $\mathrm{SiO}_{2}, \mathrm{Mn}$ monoxide, and spinel-type oxides. The low powder bed temperature of $\sim 200{ }^{\circ} \mathrm{C}$ in 
Table II. Detailed Atomic Ratio (At. Pct) for Each Element for the Given Location in Fig. 3.

\begin{tabular}{|c|c|c|c|c|c|c|c|}
\hline Powder & Location & $\mathrm{O}$ & $\mathrm{Si}$ & Mn & $\mathrm{Cr}$ & $\mathrm{Fe}$ & Compound \\
\hline \multirow[t]{4}{*}{ Medium Oxygen } & $\mathrm{P} 1$ & 59.9 & 14.9 & 12.9 & 3.6 & 2.5 & $\mathrm{Si}: \mathrm{Mn}: \mathrm{O} \approx 1: 1: 4$ \\
\hline & $\mathrm{P} 2$ & 67.6 & 21.7 & 6.0 & 0.4 & 1.3 & $\mathrm{Si}: \mathrm{Mn}: \mathrm{O} \approx 3: 1: 10$ \\
\hline & P3 & 39.0 & 2.2 & 0.6 & 30.3 & 19.1 & $\mathrm{Cr}: \mathrm{O} \approx 3: 4$ \\
\hline & P4 & 44.1 & 5.7 & - & 40.1 & 6.4 & $\mathrm{Cr}: \mathrm{O} \approx 1: 1$ \\
\hline \multirow[t]{4}{*}{ High Oxygen } & P1 & 34.9 & 1.4 & - & 32.2 & 28.2 & $\mathrm{Fe}: \mathrm{Cr}: \mathrm{O} \approx 1: 1: 1$ \\
\hline & $\mathrm{P} 2$ & 49.1 & 0.7 & - & 11.2 & 34.6 & Fe:Cr:O $\approx 3: 1: 5$ \\
\hline & P3 & 62.7 & 0.1 & - & - & 35.8 & $\mathrm{Fe}: \mathrm{O} \approx 2: 3$ \\
\hline & P4 & 61.0 & 0.1 & - & - & 37.2 & $\mathrm{Fe}: \mathrm{O} \approx 2: 3$ \\
\hline
\end{tabular}

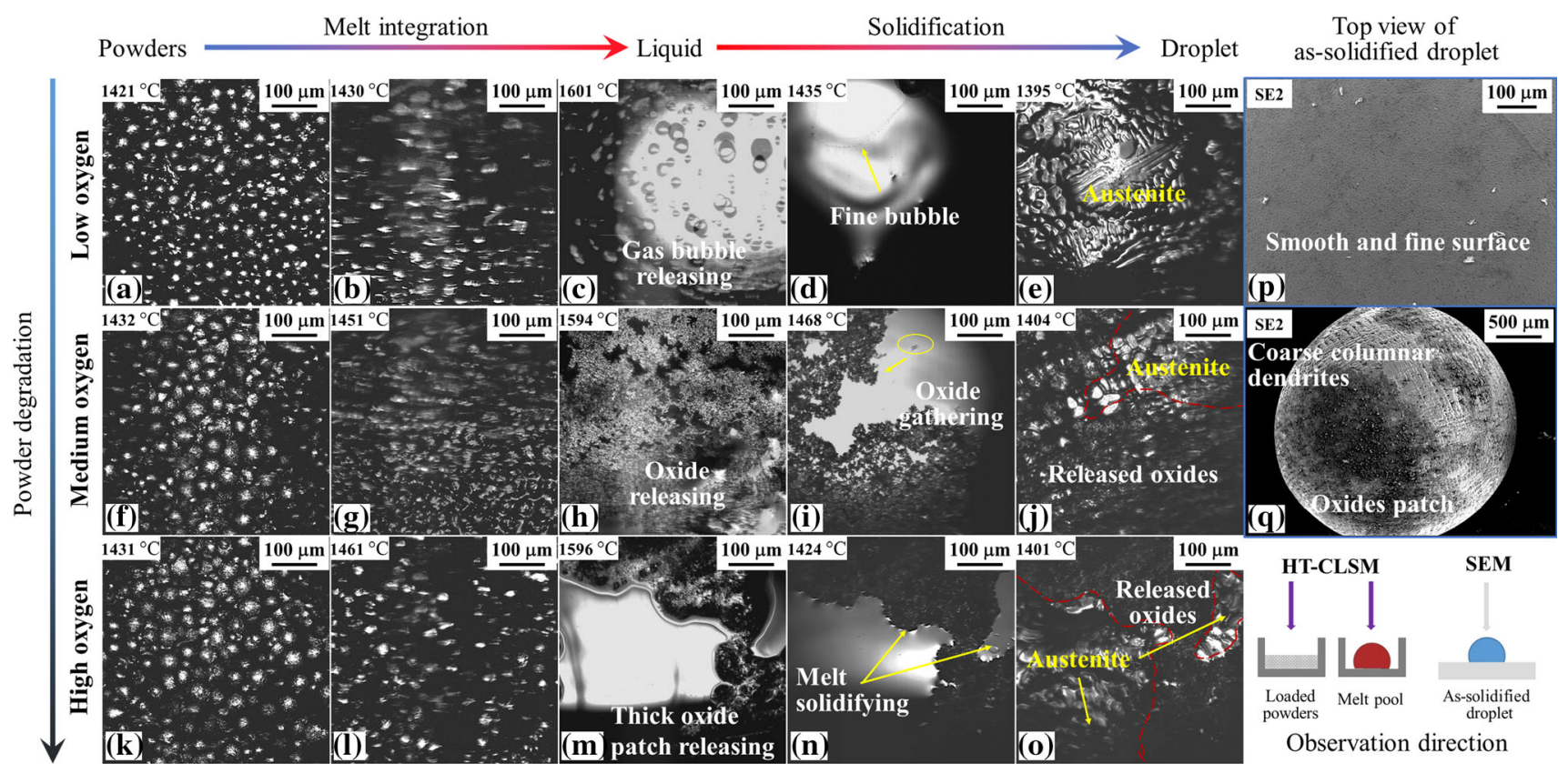

Fig. 4-HT-CLSM in-situ observation of the solidification behavior of 316L stainless steel powders with different surface oxidation conditions: $(a)$ to $(e)$ for the low $\mathrm{O}$ powder, $(f)$ to $(j)$ for the medium O powder, and $(k)$ to $(o)$ for the high $\mathrm{O}$ powder. $(p)$ and $(q)$ show the top views of the Low $\mathrm{O}$ droplet and Medium $\mathrm{O}$ droplet, respectively.

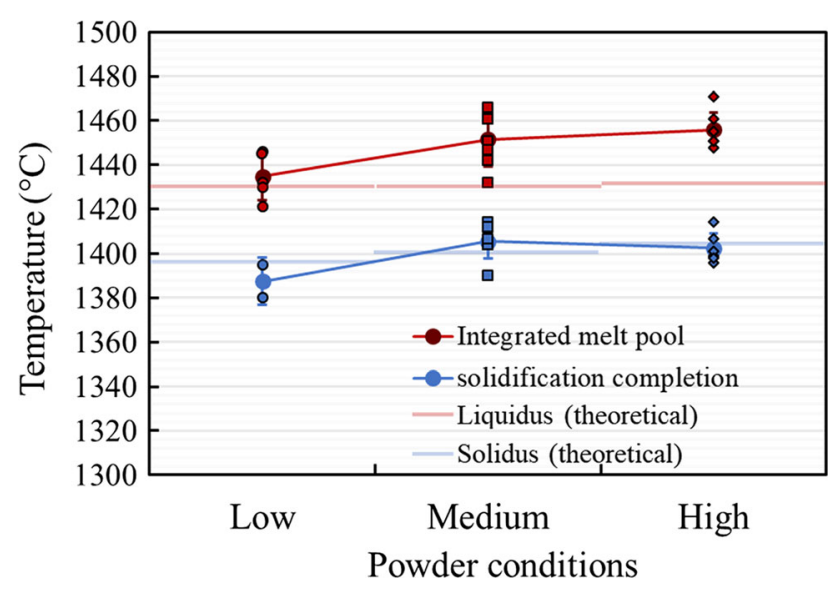

Fig. 5-The full melting temperature of the powders and the solidification completion temperature of the primary phase in the observation field of the HT-CLSM are plotted $v s$ the oxide concentration in the $316 \mathrm{~L}$ powder. the medium $\mathrm{O}$ powder oxidation favors the formation of $\mathrm{Cr}_{2} \mathrm{O}_{3}$ but suppresses the iron oxide (Figure 7(b)). For the case of high $\mathrm{O}$ powder, the $\mathrm{Fe}_{2} \mathrm{O}_{3}$ corundum phase is promoted on the powder surface because of the increased temperature and sufficient $\mathrm{O}_{2}$. At the same time, metal iron is transported through corundum-type oxides, which are involved in the formation of the $(\mathrm{Fe}$, $\mathrm{Cr}$ ) spinel phase and further outer layer $\mathrm{Fe}_{2} \mathrm{O}_{3}$ formation via outward diffusion. ${ }^{[38]}$ The STEM-EDS images shown in Figure 8 show the surface oxide cross section on the high $\mathrm{O}$ powder with the oxide formation sequence of $\mathrm{Cr}_{2} \mathrm{O}_{3} \rightarrow(\mathrm{Fe}, \mathrm{Cr})$ spinel $\rightarrow \mathrm{Fe}_{2} \mathrm{O}_{3}$ from the metal surface to the oxide layer surface. Such oxidation behavior has also been reported in previous research ${ }^{[39-41]}$ Consequently, the oxidation thermodynamic preference and outward diffusion result in a high volume fraction of iron oxide on the high $\mathrm{O}$ powder surface. 

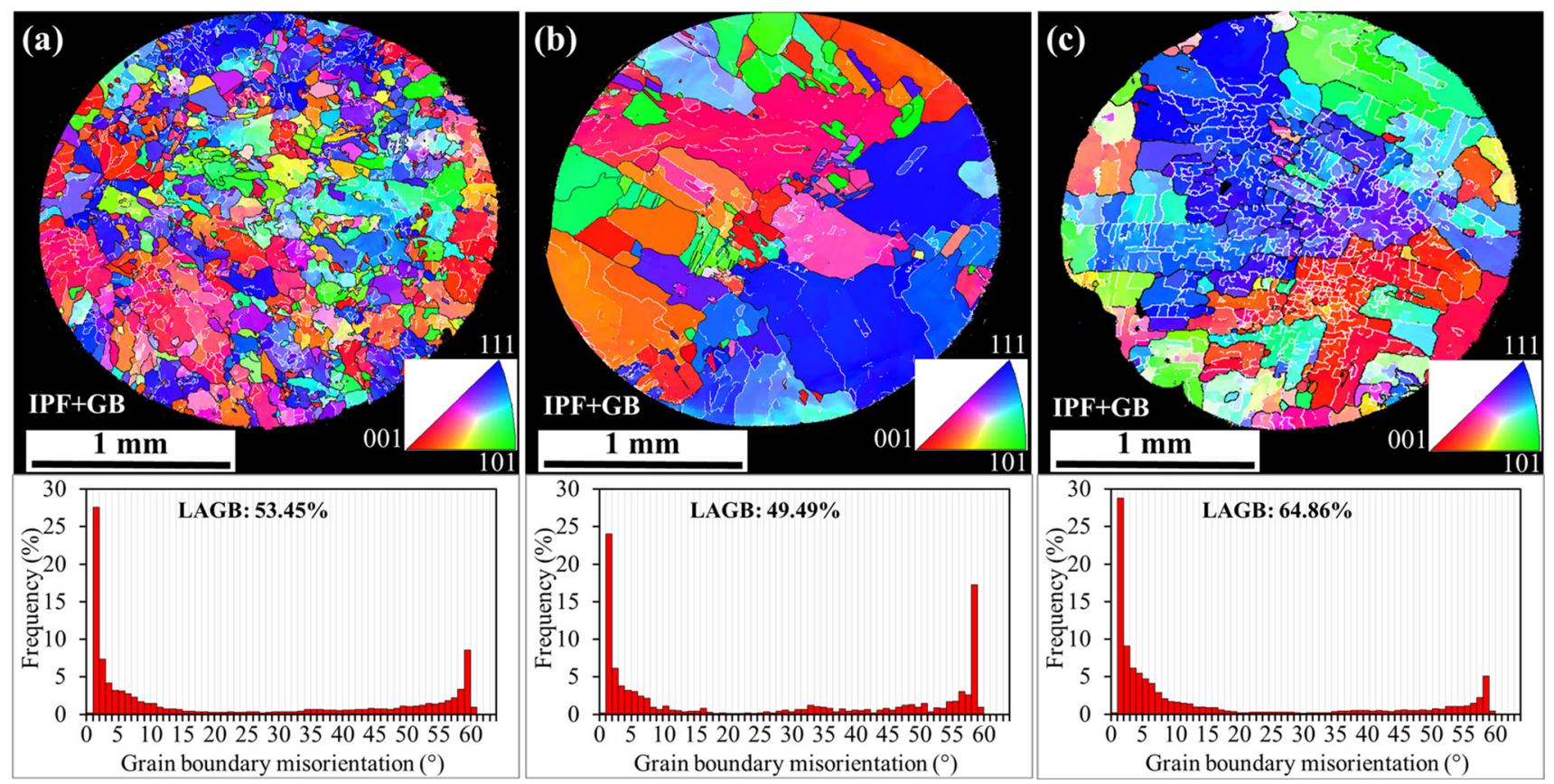

Fig. 6-EBSD analysis of as-solidified droplets prepared from the three different types of powders. The inverse pole figure image with the overlapping of the grain boundaries and their corresponding misorientation distribution is presented: $(a)$ droplet obtained from the low $\mathrm{O}$ powder, $(b)$ droplet obtained from the medium $\mathrm{O}$ powder, and $(c)$ droplet obtained from the high $\mathrm{O}$ powder.

\section{B. The Delayed Fully Melting Temperature}

The in-situ observation of the melting behavior of the 316L powders in HT-CLSM experiments presented an increase in the full melting temperature with increasing oxide content in the powders. In bulk metal melting, the liquidus is normally the same as the full melting temperature due to its structural continuity. The powder metal and alloys are on the opposite condition, where the high surface area of powder materials separates them as individual cells during melting. Powder surface characteristics are one of the key factors that influence the melting behavior of loaded powders.

In the current study, the increased full melting point is influenced by the surface oxide layer, which prevents the individual molten powder from contacting each other when the liquidus temperature is reached. Such reduced permeability for the molten powder hinders the formation of an integrated melt pool in the powder melting process. A similar phenomenon in liquid lithium was reported by Wang et al. ${ }^{[42]}$ and Ga-In liquid alloy by Khan et al. ${ }^{[43]}$ This can be attributed to the high interfacial energy and limited wetting between the melt and surrounding oxides. From the equilibrium phase calculation (Figure 9), an increased volume fraction of spinel oxides retains the solid state with increasing oxide content from the liquidus of $316 \mathrm{~L}$ alloy $\left(\sim 1430{ }^{\circ} \mathrm{C}\right)$ to $1500{ }^{\circ} \mathrm{C}$, when the liquid oxide phase first appears. These solid oxides might still be strong enough to maintain the layer formed on the molten powder surface.

According to the Young-Laplace equation, ${ }^{[44]}$ the capillary pressure $p_{\mathrm{c}}$ of the individual powder melt flow through the gap of surrounding oxides is described as $p_{\mathrm{c}}=2 \gamma \cos \theta / r_{\mathrm{c}}$, where $\gamma$ is the interfacial energy, $r_{\mathrm{c}}$ is the effective radius of the interface, and $\theta$ is the wetting angle. The surface oxide concentration on the powder influences the effective radius of the interface, where here is the unoxidized powder surface between oxide patches. A higher concentration of oxide results in a higher coverage of oxide patches on the powder surface and a smaller pure metal surface. It is more difficult for the high $\mathrm{O}$ molten powder to permeate and integrate into one melt pool due to the significantly reduced gap dimension. However, the wettability of the steel melt on the surrounding oxide increases with increasing temperature ${ }^{[45]}$ which leads to a reduced capillary pressure for the powder melt permeating the surface oxide. As compensation, a further higher temperature is presented for melt pool integration in high $\mathrm{O}$ powder melting.

Figure 10 presents a schematic illustration of the effect of surface oxides on the powder melting process. These large patches of oxides on the high $\mathrm{O}$ powder form a ceramic cage retaining the molten metal from each other due to the limited wetting of the metal melt. A higher temperature is expected to assist melt integration. In contrast, the low $\mathrm{O}$ powder melt immediately forms an integrated pool when the melting temperature reaches the liquidus temperature

The balling defect ${ }^{[46,47]}$ generated by inappropriate fusion parameters and an inefficient protective atmosphere may also appear with the surface oxide-induced cage effect in the powder fusion-based AM process from a material point of view. The presence of contamination (oxide layer) on the surface of the molten powder maintains the spherical shape of the melt owing to high surface tension, and, thus, poor wetting of the substrate. In the L-PBF process, the heating and cooling rates range from $10^{3}$ to $10^{6} \mathrm{~K} / \mathrm{s}^{[26,48]}$ Due to the limited 


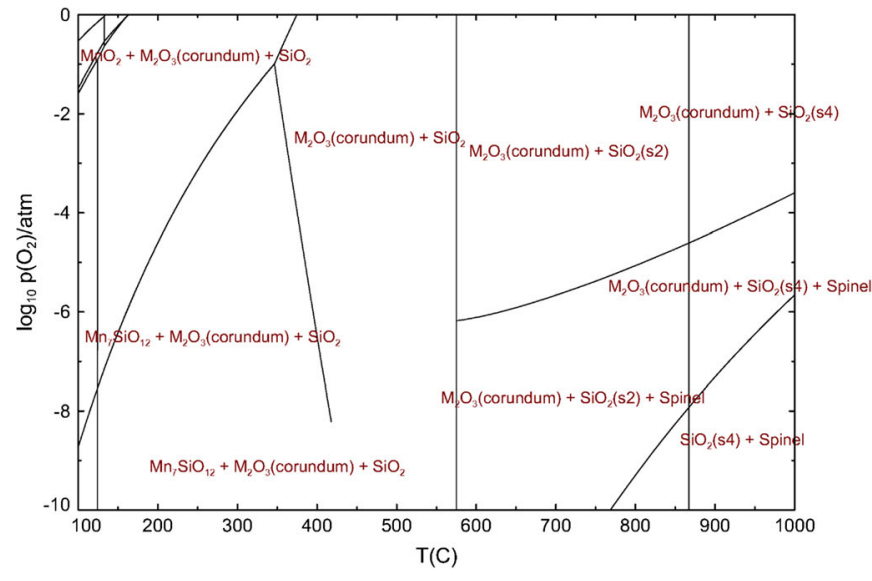

(a)

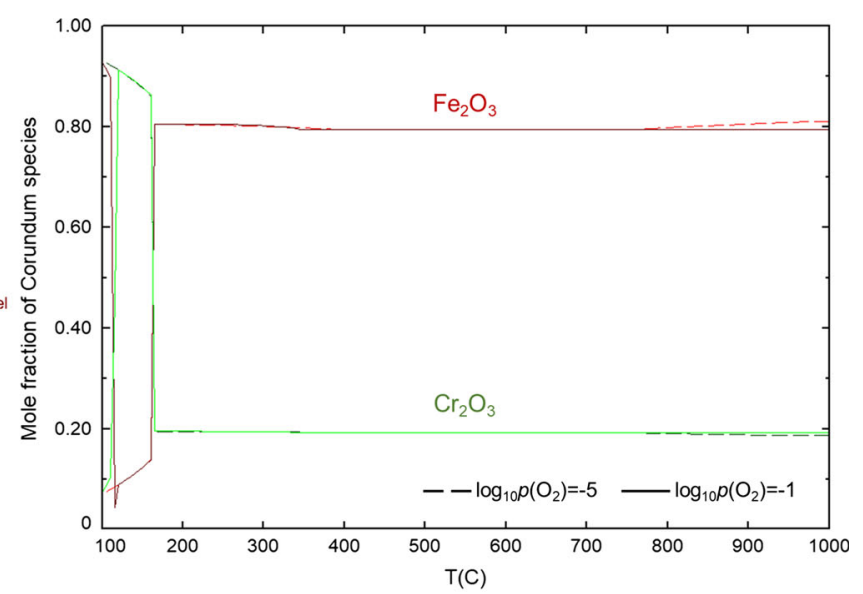

(b)

Fig. 7-The oxide phase diagram for $316 \mathrm{~L}$ stainless steel $(a)$ and the mole fraction of the $\mathrm{M}_{2} \mathrm{O}_{3}$ corundum species under different oxygen partial pressures $(b)$. The system is $\mathrm{Fe}-15.77 \mathrm{Cr}-1.26 \mathrm{Mn}-0.63 \mathrm{Si}$ under varying oxygen partial pressure. $\mathrm{Ni}$ and Mo were not considered here due to their limited oxygen affinity. The $\mathrm{M}_{2} \mathrm{O}_{3}$ corundum oxide includes $\mathrm{Fe}_{2} \mathrm{O}_{3}$ and $\mathrm{Cr}_{2} \mathrm{O}_{3}$. The $\mathrm{AB}_{2} \mathrm{O}_{4}$ spinel oxide includes $\mathrm{Fe}_{3} \mathrm{O}_{4}, \mathrm{FeCr}_{2} \mathrm{O}_{4}$, $\mathrm{MnFe}_{2} \mathrm{O}_{4}$, and $\mathrm{MnCr}_{2} \mathrm{O}_{4}$. The oxidation conditions for the three types of $316 \mathrm{~L}$ powder are listed in Table I.

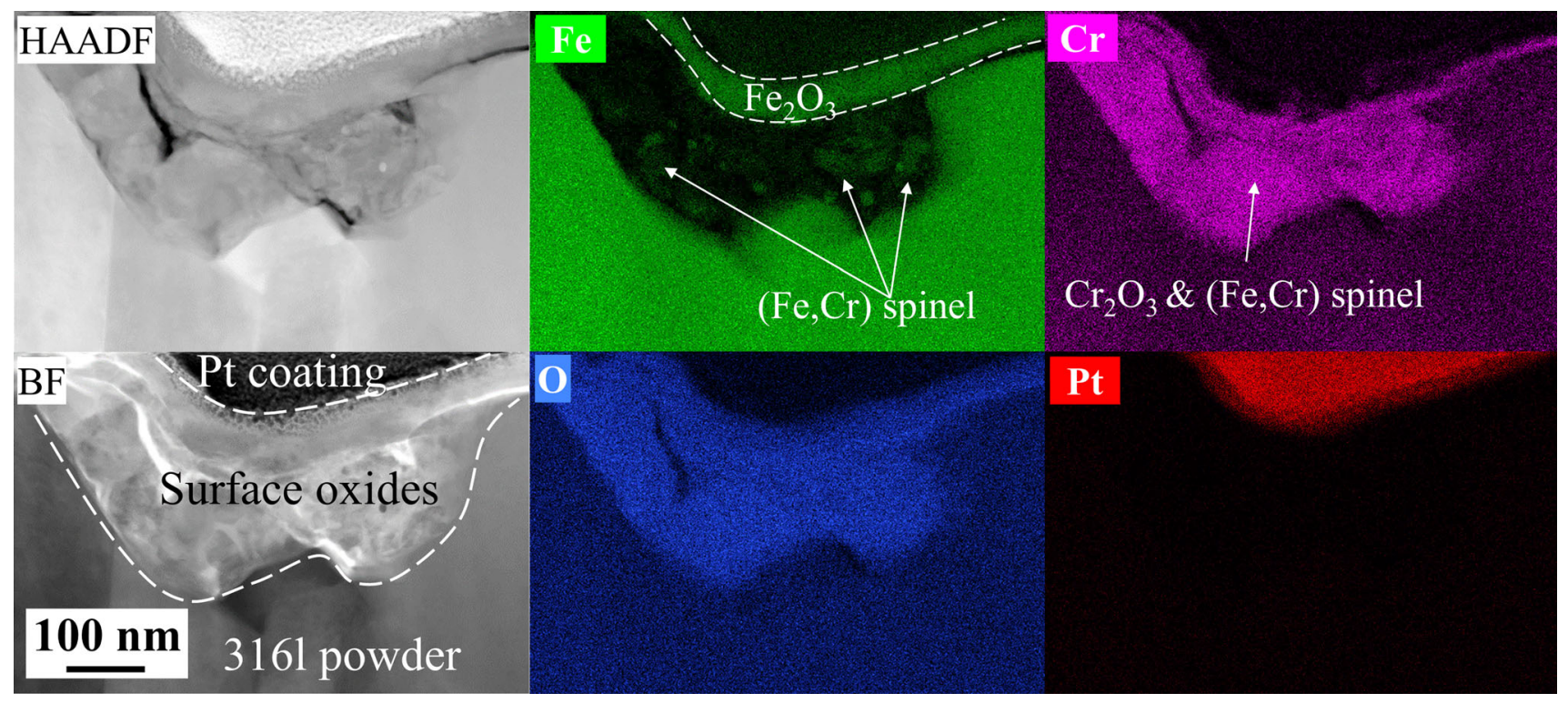

Fig. 8-STEM-EDS result for the cross section of surface oxides on the high O powder. The $\mathrm{Cr}_{2} \mathrm{O}_{3}$ and (Fe, $\mathrm{Cr}$ ) spinel and Fe $\mathrm{O}_{3}$ phases are indicated in the $\mathrm{Fe}$ and $\mathrm{Cr}$ element maps.

melting time caused by the high scanning speed of the heating source, a much higher heating temperature is required to eliminate the balling behavior induced by the cage effect. However, severe overheating of the metallic powder can inevitably raise the evaporation of low melting point solutes and affect the mechanical performance of the as-built component.

\section{The Columnar to Equiaxed Transition in Austenitic Dendrite Growth}

In general, the as-solidified grain morphology is synergistically influenced by the alloy chemical composition, inoculation, melt treatment and processing method. ${ }^{[49]}$ As the experimental procedure remains unchanged and the melt is free from any interference during heating and solidification, chemical variation and inoculation become two potential factors that affect the microstructure evolution of the as-solidified droplets.

The chemical analysis shows that the $\mathrm{Cr}$ and $\mathrm{Si}$ content in low $\mathrm{O}$ droplets and high $\mathrm{O}$ droplets changes from 15.3 to $14.6 \mathrm{wt}$ pct and 0.63 to $0.37 \mathrm{wt}$ pct, respectively. As strong oxide-forming elements, these solutes participate in surface oxidation and are incorporated into oxide compounds. ${ }^{[2]}$ Based on the Columnar to Equiaxed transition (CET) criteria established by Hunt, ${ }^{[50]}$ the fully columnar dendritic structure can be described as 


$$
G>0.617\left(N_{0}\right)^{1 / 3}\left\{1-\frac{\left(\Delta T_{\mathrm{N}}\right)^{3}}{(\Delta T)^{3}}\right\} \Delta T
$$

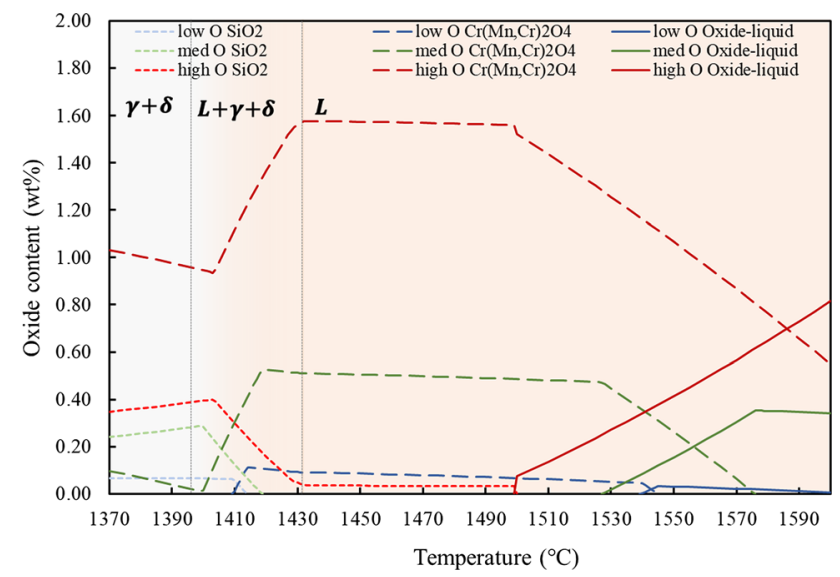

Fig. 9-The equilibrium phase predicted by Factsage 7.3 with the FSstel and FToxid databases. The increased oxide volume fraction is consistent with the oxide content in the powders. The oxide was retained in the solid state at the melt integration temperature of different $316 \mathrm{~L}$ powders.
Here

$$
\Delta T=2\left\{-\frac{2 m V\left(1-k_{0}\right) C_{0} \Gamma}{D}\right\}^{1 / 2}
$$

where $G$ is the temperature gradient, $V$ is the dendrite growth velocity, $N_{0}$ is the effective number density of heterogeneous substrate particles within the melt, $\Delta T$ is the undercooling, $\Delta T_{\mathrm{N}}$ is the undercooling at the heterogeneous nucleation temperature, $C_{0}$ is the alloy composition, $m$ is the liquidus slope, $k_{0}$ is the distribution coefficient, and $\Gamma$ is the Gibbs-Thomson coefficient (the ratio of solid-liquid interfacial energy to fusion entropy). The term $-m\left(1-k_{0}\right) C_{0}$ corresponds to the temperature difference between the liquidus and solidus at a composition of $k_{0} C_{0}$. It is proportional to the undercooling for dendrite growth. The equilibrium calculation shows that the solid-liquid coexisting region occurs at $43 \mathrm{~K}$ in the low $\mathrm{O}$ droplet sample and at $37 \mathrm{~K}$ in the high $\mathrm{O}$ droplet solidification. The reduced chemical composition leads to the reduction of growth restriction by solutes in the melt, which promotes columnar dendritic growth. With the modification of this CET criterion by considering the high-velocity effect in rapid solidification, ${ }^{[51]}$ the reduced solute elements can further stimulate columnar grain growth.
Solid powders
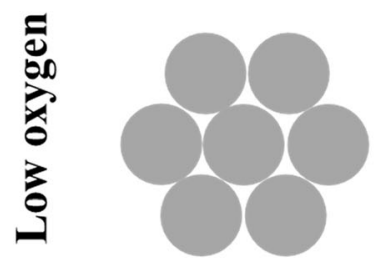

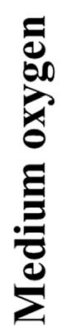
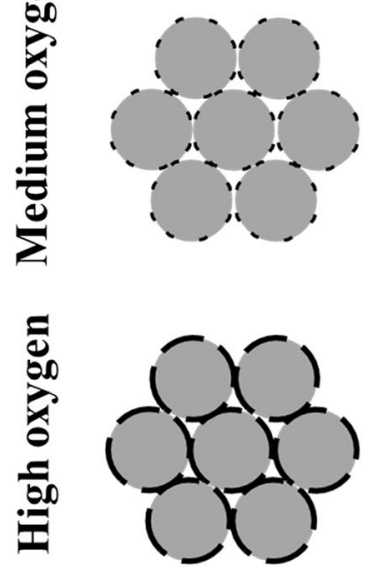

Molten powders
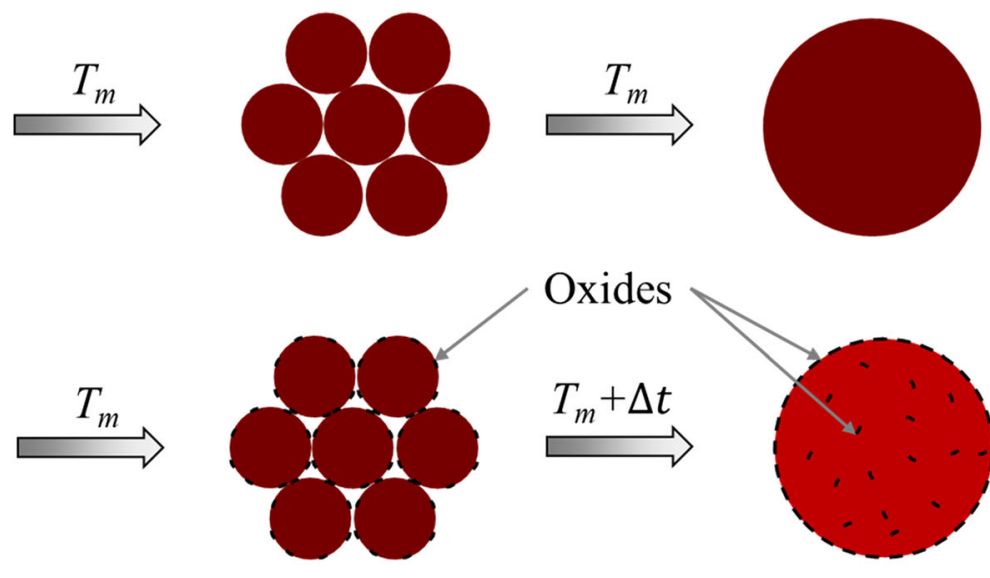

\section{Integrated melt pool}

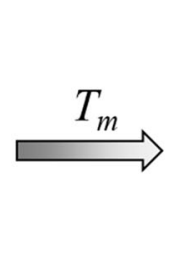

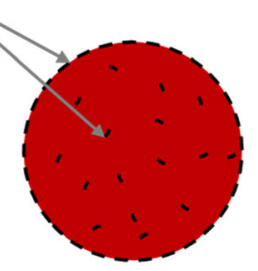
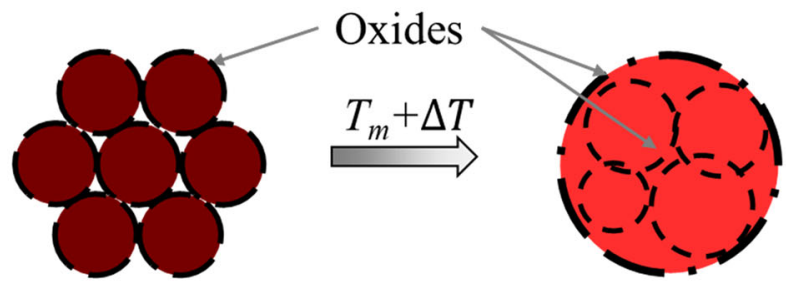

$\mathbf{0}<\Delta t<\Delta \boldsymbol{T}$

Fig. 10-A schematic illustration of the cage effect produced by the surface oxide layer of the $316 \mathrm{~L}$ powders, which requires a higher temperature to improve the wetting and interfacial tension to reduce the capillary pressure needed to filtrate the liquid within the powders to integrate with other liquid for forming one melting pool. 


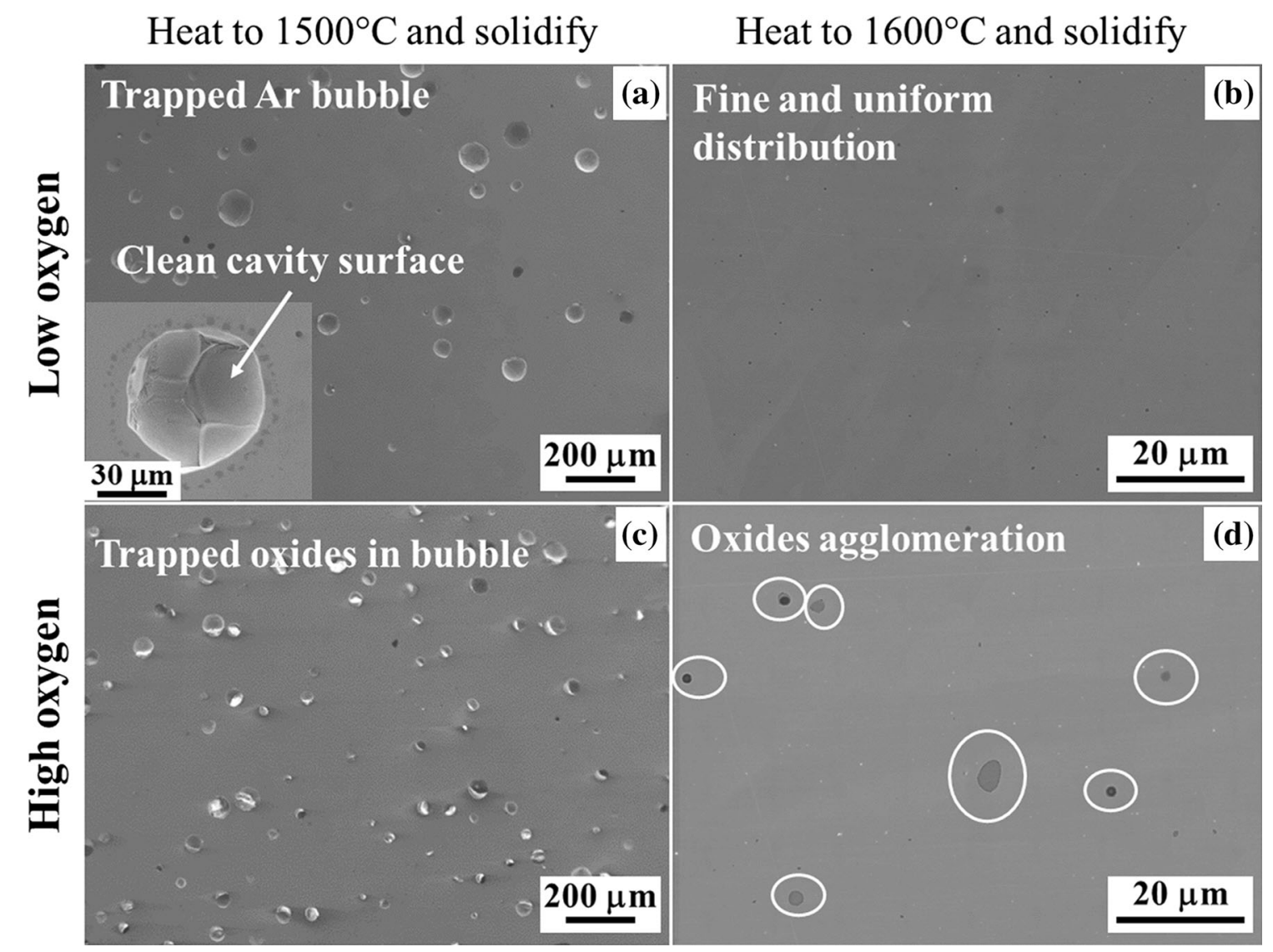

Fig. 11-Microstructure of the as-solidified droplets at different temperatures. The low $\mathrm{O}$ powder heated to $(a) 1500{ }^{\circ} \mathrm{C}$ and $(b) 1600{ }^{\circ} \mathrm{C}$ and the high $\mathrm{O}$ powder heated to $(c) 1500{ }^{\circ} \mathrm{C}$ and $(d) 1600{ }^{\circ} \mathrm{C}$. (a) and (c) were analyzed with the SE signal, and (b) and (d) were obtained under BSE contrast.

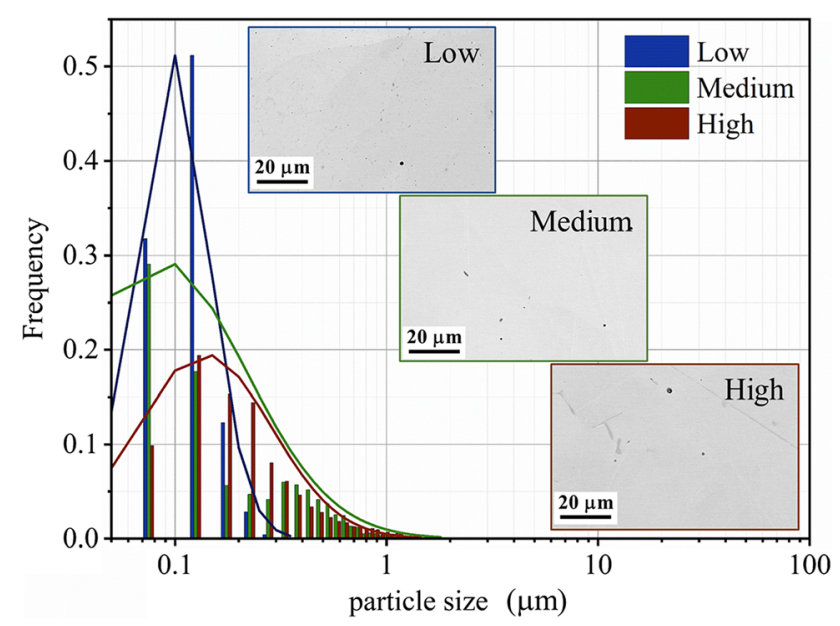

Fig. 12-Statistical analysis of the inclusions in the as-solidified droplets prepared from $316 \mathrm{~L}$ powders with different surface oxidation conditions. Low $\mathrm{O}$ droplet: volume fraction 0.189 pct, number density 0.025 per $\mu \mathrm{m}^{2}$; Medium $\mathrm{O}$ droplet: volume fraction 0.238 pct, number density 0.002 per $\mu \mathrm{m}^{2}$; High $\mathrm{O}$ droplet: volume fraction 0.321 pet, number density 0.003 per $\mu \mathrm{m}^{2}$.

To examine the redistribution of surface oxide from high $\mathrm{O}$ powder, interfered droplet samples with low $\mathrm{O}$ powder and high $\mathrm{O}$ powder were obtained by terminating heating at $1500{ }^{\circ} \mathrm{C}$ and solidifying them. The microstructures of interfered droplets and normal heating samples are shown in Figure 11.

The low $\mathrm{O}$ interfered droplet in Figure 11(a) shows the porosity via argon gas entrapment, which presents a clean inner surface in the cavity. In contrast, in the high $\mathrm{O}$ interfered droplet, the upfloating oxides from the powder surface are entrapped in the droplet with the Ar gas (Figure 11(c). With increasing temperature, such porosity and floating oxides are captured in Figures 11(b) and (d) in the melting of low $\mathrm{O}$ powder and high $\mathrm{O}$ powder, respectively. As a consequence, the low $\mathrm{O}$ sample shows a fine and uniform distribution of inclusions (oxides) and precipitates in Figure 11(b). However, large oxide agglomeration with a reduced inclusion number is observed when the majority of the surface oxides are released to the top of the high $\mathrm{O}$ droplet (Figure 11(d)). Agglomeration of inclusions is desired in the steel-making process due to the improved kinetics for inclusion into the slag layer to purify the steel. However, coarse inclusions in the highly localized powder melting can lead to degradation of mechanical performance because of stress concentration-induced early failure. ${ }^{[52]}$

The statistical measurements for the inclusions in the droplet samples shown in Figure 12 confirm that the increased oxide content of powder materials leads to a 

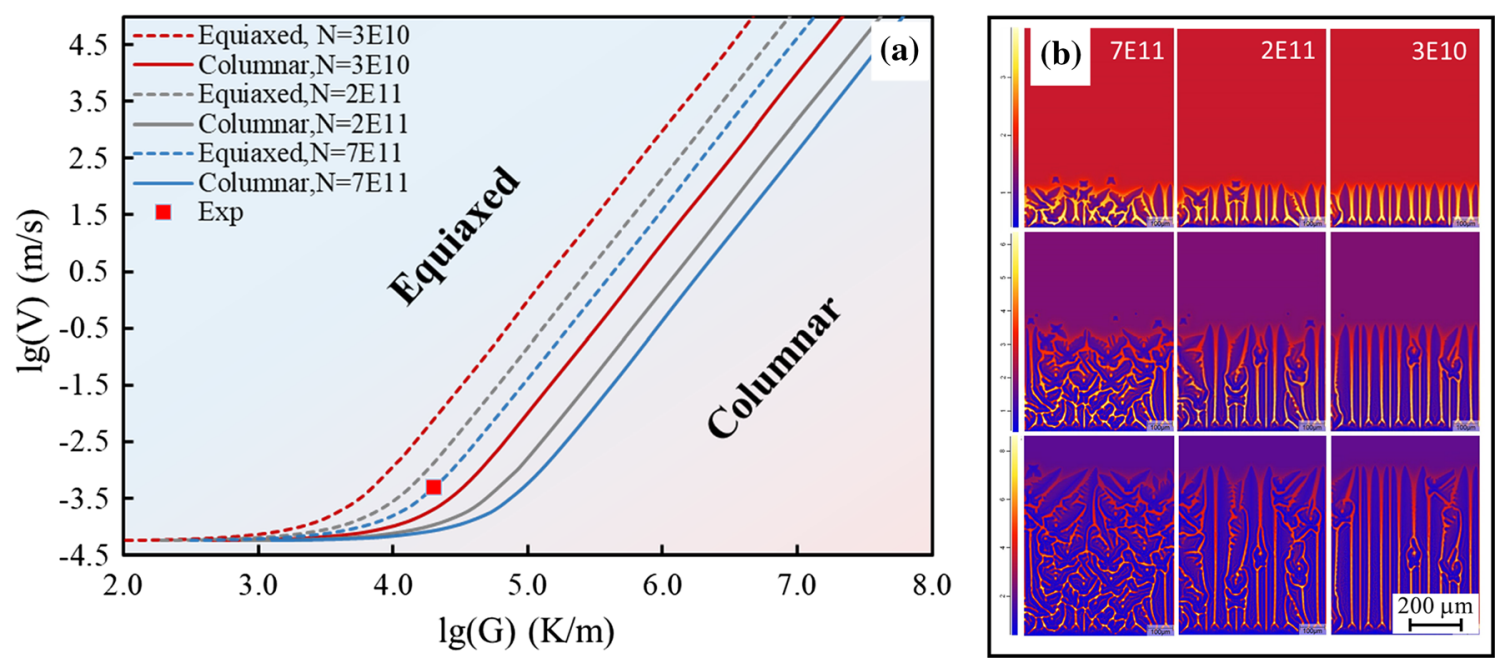

Fig. 13-The CET diagram with different nuclei number densities suggests a tendency for austenite morphology evolution (a), and the corresponding phase-field simulation shows consistent results as the microstructure of the as-solidified droplet varies with oxide content $(b)$.

higher volume fraction and larger sized inclusions in the as-solidified droplets. However, the number density of these inclusions drops in magnitude from 0.025 per $\mu \mathrm{m}^{2}$ in low $\mathrm{O}$ droplets to 0.003 per $\mu \mathrm{m}^{2}$ in high $\mathrm{O}$ droplets. This reduction in inclusion number density in the droplet samples is attributed to absorption of the in-situ formed inclusions in the melt ${ }^{[53]}$ by the entrapped oxides from powders to reduce the interface energy. A similar inclusion distribution (increased inclusion size and reduced inclusion number density for increasing powder/processing oxygen content) has also been reported in AM-processed $12 \mathrm{CrNi}_{2}$ alloy, ${ }^{[24]}$ AISI 420 stainless steel, ${ }^{[54]}$ and $316 \mathrm{~L}$ stainless steel ${ }^{[55]}$ powder materials, which suggests that inclusion agglomeration is inevitable even under AM-processing conditions. In the laser/electron beam-induced powder fusion scenario, the Marangoni effect is believed to substantially influence melt pool convection. ${ }^{[56]}$ By using the measured speed of Marangoni flow of $0.96 \mathrm{~m} / \mathrm{s}^{[56]}$ and assuming that the turbulence fluctuation reaches $50 \mathrm{pct}$, the calculated turbulence kinetic energy can reach $\sim 0.35$ $\mathrm{m}^{2} / \mathrm{s}^{2}$, which is insufficient to break up inclusions with a size smaller than $100 \mu \mathrm{m}\left(0.75 \mathrm{~m}^{2} / \mathrm{s}^{2}\right)$ according to Guan's model. ${ }^{[53]}$ Thus, the influence of the temperature-induced Marangoni effect on the agglomeration break-up is limited. From the literature ${ }^{57-59]}$ some stable inclusions in liquid steel have been proven to be austenite grain refiners with varying solidification conditions. Together with the above evaluation of the inclusions in the droplets, it is indicated that potential nucleation sites for austenite can be reduced in the high $\mathrm{O}$ droplet due to inclusion agglomeration.

From the measured grain size $(90 \mu \mathrm{m}$ for the low $\mathrm{O}$ droplet) and width of the columnar dimension (145 and $244 \mu \mathrm{m}$ for medium and high $\mathrm{O}$ droplets, respectively), the grain number densities of the three droplets are estimated to be around the level of $7 \times 10^{11} \mathrm{~m}^{-3}$ (low $\mathrm{O}$ droplet), $2 \times 10^{11} \mathrm{~m}^{-3}$ (medium $\mathrm{O}$ droplet), and $3 \times 10^{10}$ $\mathrm{m}^{-3}$ (high $\mathrm{O}$ droplet) based on the equation $N_{\mathrm{g}}=0.5 /$ $d^{3}{ }^{[60]}$ where $N_{\mathrm{g}}$ is the grain number density and $d$ is the grain size. Thus, on the basis of the CET model, ${ }^{[50]}$ the CET diagram for the austenite grain morphology selection is calculated and shown in Figure 13(a), in which the nucleation undercooling used is $2 \mathrm{~K}$. The growth velocity of the dendritic tip used here is mainly obtained from References 61, 62 but with a smaller exponent (3) compared with the value (3.12) in References 61,62 , as the temperature gradient in this work is smaller than that in the references. The experimental condition in this work is also shown in Figure 13a by the red square. As shown in Figure 13a, the low $\mathrm{O}$ droplet in this work falls in the full equiaxed grain region, while the medium and high $\mathrm{O}$ droplets all lie in the equiaxed and columnar mixing region.

To further reveal the morphological evolution of austenite grains, 2D phase-field simulations were carried out with different effective nucleation site number densities (the same as that used in the calculation of the CET diagram), which are presented in Figure 13(b). MICRESS software ${ }^{[63]}$ was used here for the phase-field simulations. The details of the theory and the setup have been described in Reference 34. Similar to the analytical model prediction shown in Figure 13(a), the microstructures observed in the as-solidified droplets were reproduced by governing heterogeneous nucleation during melt solidification. With a number density of the heterogeneous nucleation sites of $7 \times 10^{11} \mathrm{~m}^{-3}$ for low $\mathrm{O}$ droplets, the grain morphology under the current experimental conditions falls into the full equiaxed structure region (the blue-dashed line is the boundary of the equiaxed structure), where the phase-field simulation shows the same tendency as that for the equiaxed structure in the left column in Figure 13(b). In contrast, a columnar dominant structure with limited equiaxed grains is observed in the right column in Figure 13(b) with a nuclei number density of $3 \times 10^{10} \mathrm{~m}^{-3}$ in a high O droplet, which approaches the full columnar region boundary shown by the red solid line in the CET diagram shown in Figure 13(a). Based on the consistent results obtained from the solidification experiment and theoretical analysis, the effective number 

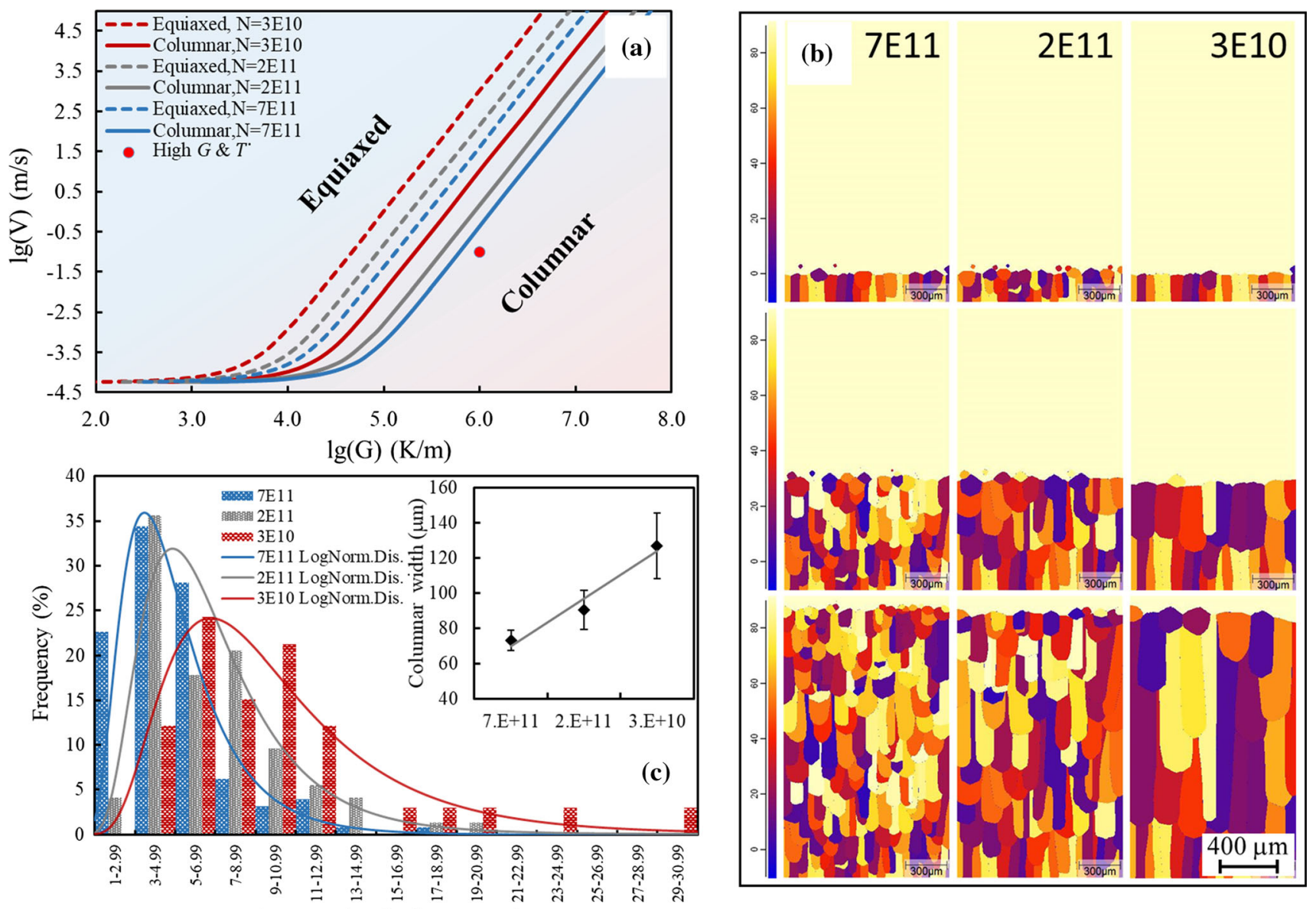

Aspect ratio of columnar grains

Fig. 14-The CET diagram with different nuclei number densities suggests a tendency for a columnar morphology for the austenite phase during the solidification under a high cooling rate $(\dot{T})$ and thermal gradient $(G)(a)$, the corresponding phase-field simulation showing the grain morphology $(b)$, and the columnar grain width and aspect ratio extracted from phase-field simulation $(c)$.

density of the heterogonous nucleation particles greatly influences the as-solidified microstructure of $316 \mathrm{~L}$ powders with varying oxide content.

To reveal the microstructure evolution in the powder fusion-based AM process, a high cooling rate $\left(10^{5} \mathrm{~K} / \mathrm{s}\right)$ and high thermal gradient $\left(10^{6} \mathrm{~K} / \mathrm{m}\right)$ condition were used as inputs for the calculation (Figure 14) with the powder condition of nuclei number densities resulting from varying oxide content. The columnar morphology was predicted by the CET model (Figure 14(a)). The oxide agglomeration results in a decrease in the nuclei number density of the heterogenous nucleation site, which leads to a coarsening of the columnar morphology of the as-solidified grains, as exhibited in the phase-field simulation (Figure 14(b)). A statistical analysis of the simulation data in Figure 14(c) suggested that an enlarged columnar aspect ratio and increased columnar grain width are present under the rapid solidification of the high $\mathrm{O}$ powder condition compared to the low $\mathrm{O}$ powder condition. Generally, a coarse columnar structure is not desired due to its higher hot cracking tendency and severe performance anisotropy for the as-built component. This shows that the powder oxide content is critical to the as-solidified microstructure in the powder fusion-based AM process.
Based on the above discussion, the surface oxides formed on the steel powders can influence powder melting and solidification. The surface oxides delay the melt integration of molten powders due to the cage effect, which reduces melt permeability caused by the poor wetting of liquid steel on these oxides. Additionally, surface oxidation modifies the steel composition by the consumption of solute elements with high oxygen affinity. These oxides leftover in the melt lead to inclusion agglomeration, which alters the solidification behavior and as-solidified microstructure. As a result, deterioration of the mechanical performance of the as-built component is expected.

\section{CONCLUSIONS}

In the current work, we studied the effect of surface oxides on the melting and solidification of AM-grade 316L stainless steel powders by experimental observation and theoretical analysis. The following conclusions were drawn:

1. The surface oxidation of the powder significantly alters its melting and solidification behavior. An increased full melting temperature is observed with 
increasing oxide content in the steel powders. This is caused by the reduced permeability of liquid steel due to the cage effect of the surface oxide layer, which originates from poor wetting of liquid steel on the oxide substrate.

2. Due to oxide entrapment during the liquid-to-solid phase transformation, the as-solidified droplet obtained from the high $\mathrm{O}$ powder shows a higher inclusion fraction with a larger particle size, which leads to an increased LAGB fraction compared to the case of low $\mathrm{O}$ powder.

3. As for the formation process for the oxides, surface oxidation modifies the chemical composition of steel powder by taking $\mathrm{Cr}, \mathrm{Mn}$, and $\mathrm{Si}$ solutes as cation elements in the stable oxide system due to their high oxygen affinity. The higher surface oxide content leads to solute element loss in the steel powder. The decrease in these solute elements promotes columnar grain growth.

4. The entrapped oxides in the high $\mathrm{O}$ melt result in inclusion agglomeration with a larger particle size and lower number density, which reduces the number density of heterogeneous substrates for nucleation. As a result, the low $\mathrm{O}$ droplet presents a fully equiaxed microstructure, while undesired columnar grains are observed in the high $\mathrm{O}$ droplet.

5. By using the solidification conditions of a high cooling rate and high thermal gradient similar to the powder fusion-based AM process, a columnar morphology is predicted for all three powder conditions. An undesired coarse and elongated columnar structure is promoted by considering inclusion agglomeration under the high $\mathrm{O}$ powder condition. In contrast, a fine columnar structure with a small aspect ratio is predicted for the low $\mathrm{O}$ powder condition.

\section{ACKNOWLEDGMENTS}

This work is financially supported by EPSRC with Grant No. EP/N011368/1. The authors would like to thank Professor H. Assadi at Brunel University London, Professor B.K. Dhindaw at the Indian Institute of Technology Bhubaneswar for the constructive discussion, and Dr Sabrina Yan for technical support with the characterization facilities within WMG, the University of Warwick.

\section{CONFLICT OF INTEREST}

On behalf of all authors, the corresponding author states that there is no conflict of interest.

\section{OPEN ACCESS}

This article is licensed under a Creative Commons Attribution 4.0 International License, which permits use, sharing, adaptation, distribution and reproduction in any medium or format, as long as you give appropriate credit to the original author(s) and the source, provide a link to the Creative Commons licence, and indicate if changes were made. The images or other third party material in this article are included in the article's Creative Commons licence, unless indicated otherwise in a credit line to the material. If material is not included in the article's Creative Commons licence and your intended use is not permitted by statutory regulation or exceeds the permitted use, you will need to obtain permission directly from the copyright holder. To view a copy of this licence, visit http://creat ivecommons.org/licenses/by/4.0/.

\section{REFERENCES}

1. J.M. Capus: Metal Powders: A Global Survey of Production, Applications and Markets 2001-2010, 4th ed., Elsevier Advanced Technology, Oxford, 2005, pp. 121-52.

2. E. Hryha, R. Shvab, H. Gruber, A. Leicht, and L. Nyborg: Metall. Italiana, 2018, vol. 3, pp. 34-39.

3. A. Basak and S. Das: Annu. Rev. Mater. Res., 2016, vol. 46, pp. 125-49.

4. H. Karlsson, L. Nyborg, and S. Berg: Powder Metall., 2005, vol. 48 , pp. $51-58$.

5. I. Nyborg, T. Tunberg, and P. Wang: Metal Powder Rep., 1990, vol. 45 , pp. $750-53$.

6. P. Bracconi and G. Gasc: Metall. Mater. Trans. A, 1994, vol. 25A, pp. 509-20.

7. E. Johansson and L. Nyborg: Surf. Interface Anal., 2000, vol. 30, pp. 333-36.

8. Y. Hedberg, M. Norell, J. Hedberg, P. Szakálos, P. Linhardt, and I. Odnevall-Wallinder: Powder Matell., 2013, vol. 56, pp. 158-63.

9. L. Nyborg, A. Nylund, and I. Olefjord: Surf. Interface Anal., 1988, vol. 12, pp. 110-14.

10. Z. Munir: J. Mater. Sci., 1979, vol. 14, pp. 2733-40

11. T. DebRoy, T. Mukherjee, J. Milewski, J. Elmer, B. Ribic, J. Blecher, and W. Zhang: Nat. Mater., 2019, vol. 18, pp. 1026-32.

12. J.H. Tan, W.L.E. Wong, and K.W. Dalgarno: Addit. Manuf., 2017, vol. 18 , pp. 228-55.

13. E. Garboczi and N. Hrabe: Addit. Manuf., 2019, vol. 31, p. 100965

14. A.B. Spierings, M. Voegtlin, T. Bauer, and K. Wegener: Prog. Addit. Manuf., 2016, vol. 1, pp. 9-20.

15. Z. Snow, R. Martukanitz, and S. Joshi: Addit. Manuf., 2019, vol. 28, pp. 78-86.

16. S.E. Brika, M. Letenneur, C.A. Dion, and V. Brailovski: Addit. Manuf., 2020, vol. 31, p. 100929.

17. I.E. Anderson, E.M. White, and R. Dehoff: Curr. Opin. Solid State Mater. Sci., 2018, vol. 22, pp. 8-15.

18. J. Capus: Metal Powder Rep., 2019, vol. 75, pp. 148-50.

19. D. Herzog, V. Seyda, E. Wycisk, and C. Emmelmann: Acta Mater., 2016, vol. 117, pp. 371-92.

20. A.T. Sutton, C.S. Kriewall, M.C. Leu, J.W. Newkirk, and B. Brown: Addit. Manuf., 2020, vol. 31, p. 100904

21. M. Simonelli, C. Tuck, N.T. Aboulkhair, I. Maskery, I. Asheroft, R.D. Wildman, and R. Hague: Metall. Mater. Trans. A, 2015, vol. 46 A, pp. $3842-51$.

22. F. Yan, W. Xiong, E. Faierson, and G.B. Olson: Scr. Mater., 2018, vol. 155, pp. 104-08.

23. P. Quinn, S. O'Halloran, J. Lawlor, and R. Raghavendra: $A d v$. Mater. Process. Technol., 2019, vol. 5, pp. 348-59.

24. Z. Dong, H. Kang, Y. Xie, C. Chi, and X. Peng: Mater. Lett., 2019, vol. 236, pp. 214-17.

25. A. Gatto, E. Bassoli, and L. Denti: Addit. Manuf., 2018, vol. 24, pp. 13-19

26. C.L.A. Leung, S. Marussi, M. Towrie, R.C. Atwood, P.J. Withers, and P.D. Lee: Acta Mater., 2019, vol. 166, pp. 294-305. 
27. A.T. Sutton, C.S. Kriewall, M.C. Leu, J.W. Newkirk: Solid Freeform Fabrication 2016: Proceedings of the 27th Annual International Solid Freeform Fabrication Symposium, 2016, pp. 1004-30.

28. Carpenter Additive technical data sheet CT PowderRange 316L F, https://www.carpenteradditive.com/hubfs/carpenter_additive/ima ge/Resources/Datasheets/CT\%20PowderRange\%20316L\%20F.p df. Accessed 10th November 2020.

29. Renishaw data sheet ss 316L-0407 powder for additive manufacturing, https://www.renishaw.com/media/pdf/en/f8cba72a843440d 3bd8a09fd5021ad89.pdf. Accessed 10th November 2020.

30. J. Zhou, H. Tsai, and P. Wang: J. Heat Trans., 2005, vol. 128, pp. 680-90.

31. W. Mu, P. Hedström, H. Shibata, P.G. Jönsson, and K. Nakajima: JOM, 2018, vol. 70, pp. 2283-95.

32. J. Li, D. Bhattacharjee, X. Hu, D. Zhang, S. Sridhar, and Z. Li: Metall. Mater. Trans. B, 2019, vol. 50B, pp. 1931-48.

33. C. Zhao, C. Kwakernaak, Y. Pan, I. Richardson, Z. Saldi, S. Kenjeres, and C.R. Kleijn: Acta Mater., 2010, vol. 58, pp. 6345-57.

34. J. Eiken: A Phase-field Model for Technical Alloys Solidification, Doctoral thesis, Aachen University, Aachen, 2010.

35. F. Tang, R.J.M. Taylor, J.F. Einsle, C.S. Borlina, R.R. Fu, B.P. Weiss et al.: Proc. Natl. Acad. Sci. USA, 2019, vol. 116, pp. 407-12.

36. H.J.T. Ellingham: J. Soc. Chem. Ind. Lond., 1944, vol. 63, pp. 125-33.

37. N. Birks, G.H. Meier, and F.S. Pettit: Introduction to the High Temperature Oxidation of Metals, Cambridge University Press, Cambridge, 2006.

38. K. Habib, M. Damra, J. Saura, I. Cervera, and J. Bellés: Int. J. Corros., 2011, vol. 2011, p. 824676.

39. T. Tanabe and S. Imoto: Trans. J. I. M., 1979, vol. 20, pp. 507-15.

40. K. Nomura and Y. Ujihira: J. Mater. Sci., 1990, vol. 25, pp. $1745-50$.

41. N. Karimi, F. Riffard, F. Rabaste, S. Perrier, R. Cueff, C. Issartel, and H. Buscail: Appl. Surf. Sci., 2008, vol. 254, pp. 2292-99.

42. J. Wang, H. Wang, J. Xie, A. Yang, A. Pei, C. Wu, F. Shi, Y. Liu, D. Lin, and Y. Gong: Energy Storage Mater., 2018, vol. 14, pp. $345-50$.

43. M.R. Khan, C.B. Eaker, E.F. Bowden, and M.D. Dickey: Proc. Natl. Acad. Sci. USA, 2014, vol. 111, pp. 14047-51.
44. H. Ibach: Physics of Surfaces and Interfaces, Springer-Verlag, Berlin Heidelberg, 2006, pp. 149-206.

45. M. Humenik, Jr. and W.D. Kingery: J. Am. Ceram. Soc., 1954, vol. 37, pp. 18-23.

46. D. Gu and Y. Shen: Mater. Design, 2009, vol. 30, pp. 2903-10.

47. R. Li, J. Liu, Y. Shi, L. Wang, and W. Jiang: Int. J. Adv. Manuf. Technol., 2012, vol. 59, pp. 1025-35.

48. A. Prasad, L. Yuan, P. Lee, M. Patel, D. Qiu, M. Easton, and D. StJohn: Acta Mater., 2020, vol. 195, pp. 392-403.

49. W. Kurz, D.J. Fisher: Fundamentals of solidification, 4th revised ed., Trans Tech Publication Ltd, Zurich, 1989, pp. 63-92.

50. J.D. Hunt: Mater. Sci. Eng., 1984, vol. 65, pp. 75-83.

51. M. Gäumann, R. Trivedi, W. Kurz, Mater. Sci. Eng., 1997, vol. 226-228A, pp. 763-69.

52. X. Lou, P.L. Andresen, and R.B. Rebak: J. Nucl. Mater., 2018, vol. 499, pp. 182-90.

53. H. Duan, Y. Ren, B.G. Thomas, and L. Zhang: Metall. Mater. Trans. B, 2019, vol. 50B, pp. 36-41.

54. M. Song, X. Lin, F. Liu, H. Yang, and W. Huang: Mater. Des., 2016, vol. 90, pp. 459-67.

55. D. Eo and S. Park: J. Cho. Mater. Des., 2018, vol. 155, pp. 212-19.

56. S. Clark, C. Leung, Y. Chen, L. Sinclair, S. Marussi, P. Lee: IOP Conf. Series: Mater. Sci. Eng., 2020, vol. 861, 012010.

57. N.H. Tyas: Grain Refinement of Austenitic Stainless Steel Welds to Facilitate Ultrasonic Inspection, Doctoral Thesis, University of Cambridge, 2000, pp. 61-73.

58. G.V. Pervushin and H. Suito: ISIJ Int., 2001, vol. 41, pp. 748-56.

59. S. Lekakh, J. Ge, V. Richards, R. O'Malley, and J. TerBush: Metall. Mater. Trans. B, 2017, vol. 48B, pp. 406-19.

60. A.L. Greer, A.M. Bunn, and A. Tronche: Acta Mater., 2000, vol. 48, pp. 2823-35.

61. W. Tan and Y.C. Shin: Comput. Mater. Sci., 2015, vol. 98, pp. 446-58.

62. R. Shi, S.A. Khairallah, T.T. Roehling, T.W. Heo, J.T. McKeown, and M.J. Matthews: Acta Mater., 2020, vol. 184, pp. 284-305.

63. The microstructure Evolution Simulation Software (MICRESS), micress.rwth-aachen.de. Accessed 30th June 2020.

Publisher's Note Springer Nature remains neutral with regard to jurisdictional claims in published maps and institutional affiliations. 